\title{
Perspectives for Ginsenosides in Models of Parkinson's Disease
}

\author{
Wolf-Dieter Rausch ${ }^{*, \#}$, Lin Wei-Ming ${ }^{* *}$, Gabriele Gille**** and Khaled Radad***** \\ *Institute for Medical Chemistry, Veterinary Medical University, Vienna, Austria, \\ **Yangling University, Shaanxi, China, \\ ***Department of Neurology, Technical University, Dresden, Germany \\ ****Department of Pathology, Faculty of Veterinary Medicine, Assiut University, Egypt.
}

(Received June 19, 2007; Accepted September 1, 2007)

\begin{abstract}
Ginseng, the root of Panax species, is a well-known herbal medicine. It has been used as traditional medicine in Korea, China and Japan for thousands of years and now is a popular and worldwide natural medicine. The active principles of ginseng are ginsenosides which are also called ginseng saponins. Traditionally ginseng has been used primarily as a tonic to invigorate weak body functions and help the restoration of homeostasis. Current in vivo and in vitro studies demonstrate its beneficial effects in a wide range of pathological conditions such as cardiovascular diseases, cancer, immune deficiency and hepatotoxicity. Moreover, recent research indicates that some of ginseng's active ingredients exert beneficial actions on aging and neurodegenerative disorders such as Parkinson's disease. Essentially, antioxidant, antiinflammatory, anti-apoptotic and immunostimulant activities are mostly underlying the postulated ginseng-mediated protective mechanisms. Next to animal studies, data from neural cell cultures contribute to the understanding of these mechanisms which involve decreasing nitric oxide, scavenging of free radicals and counteracting excitotoxicity. This paper focuses on own and other neuroprotective data on ginseng for dopaminergic neurons and intends to show aspects where neuroprotection e.g. by ginsenosides, additionally or preceding standard Parkinson therapy, could come about as a valuable contribution to slow neurodegenerative processes.
\end{abstract}

Key words : Ginsenosides, Parkinson's disease, dopaminergic, neuroprotection

\section{INTRODUCTION}

Parkinson's disease (PD) as a common progressive neurodegenerative disorder is characterised by massive depletion of striatal dopamine as a result of the degeneration of dopaminergic neurons in the substantia nigra. Clinically, the disease is manifested by bradykinesia, resting tremor, rigidity and disturbance of posture and gait ${ }^{1}$. However still to date, the etiopathogenesis of nigral dopaminergic neuron loss in PD is unclear. The presence of ongoing oxidative stress as the result of inefficacious antioxidant defence mechanisms and generation of radical oxygen species in the substantia nigra of the parkinsonian brain are important pathogenetic mechanisms ${ }^{2}$. It should be noted that part of these free radicals are inevitably produced by dopamine metabolism in the brain either enzymatically through the action of monoamine oxidase B or

\footnotetext{
${ }^{\#}$ To whom correspondence should be addressed.

(Tel) +43-250-77-4209; (Fax) +43-250-77-4200

(E-mail)wolf.rausch@vu-wien-ac-at
}

by autooxidation ${ }^{3,4)}$. Therefore, an effective anti-parkinsonian therapy should not only alleviate the disease-associated symptoms, but should also interfere with the progressive dopaminergic death in the substantia nigra. Primary cell cultures of mesencephalic dopaminergic neurons have contributed to the understanding of molecular processes when using neurotoxic compounds that mimick cell death in PD. They also have the potential to analyse neuroprotective compounds for their ability to counteract these processes. Ginsenosides as the active ingredients in Panax ginseng are known for their anti-inflammatory, immunostimulant, antioxidative and possibly neurotrophic properties. Given their importance as a medication and health medicine their potential to dopaminergic cells in different PD cell models is analysed. However, it first it appears essential to consider the current therapeutic options and underlying theories of PD therapy to understand the need for further improvements or alternative strategies. 


\section{Treatment of Parkinson's disease with levodopa}

Since its introduction by Birkmayer and Hornykiewicz ${ }^{5)}$ levodopa remained the most effective drug for the symptomatic treatment of PD. Its effect for Parkinsonian patients is primarily based on its ability as a dopamine precursor to compensate the decrease of dopamine in the brain. Although the initial use of levodopa replacement therapy is effective in symptomatic treatment of PD, the clinical efficacy often declines after long-term therapy and additionally disabling side-effects appear, most notably motor fluctuations such as the wearing-off or on-off phenomena and dyskinesia ${ }^{6}$. These motor response complications appear in most patients with advanced PD treated with levodopa. The precise mechanisms for the appearance of these treatment-related fluctuations are not clear. $\mathrm{Nutt}^{7)}$ reported that the long-duration response that characterizes the first few years of levodopa use in Parkinsonian patients appears to depend on the integrity of remaining dopaminergic nerve terminals in the striatum which retain the capacity to synthesize, release, reuptake and store newly synthesized dopamine. After long-term use of levodopa and with progression of the disease, the short-duration response to levodopa and appearance of motor fluctuations are paralleled with dopaminergic denervation and loss of release and reuptake capacity ${ }^{8}$.

\section{Effect of levodopa on dopaminergic cells}

Though dopamine replacement therapy with levodopa is successful to improve PD symptoms, it does not inhibit the progressive degeneration of dopaminergic neurons in the substantia nigra. Levodopa is not only ineffective against death of dopaminergic cells in PD patients, but there is also serious concern about possible toxic actions of levodopa to the remaining dopaminergic neurons. It has been reported that this compound is toxic to cultured dopaminergic neurons ${ }^{9,10)}$. On the other hand, there is evidence indicating that large doses of levodopa do not induce dopamine neuron degeneration in mice, rats and human ${ }^{11-13)}$. In PD patients, it was speculated that the remaining dopaminergic neurons in the patient's brain could be particularly vulnerable to levodopa toxicity since they are hyperactive as a consequence of compensatory mechanisms ${ }^{14)}$. In contrast, Dziewczapolski et al. ${ }^{15)}$ and Murer et al. ${ }^{16)}$ reported that treatment of rats with different degree of nigrostriatal damage for 6 months with oral levodopa was not toxic for remaining dopaminergic neurons. Even when levodopa administration is started during an active degenerative process of dopaminergic neurons after intrastriatal 6-hydroxydopamine (6-OHDA) injec- tion, no aggravation of toxicity was found ${ }^{17)}$.

\section{Mechanisms underlying levodopa toxicity}

It was reported that increasing oxidative stress via autooxidation of levodopa plays an important role in levodopa toxicity. Autooxidation and metabolism of levodopa can give rise to potentially harmful free radical species, hydrogen peroxide $\left(\mathrm{H}_{2} \mathrm{O}_{2}\right)$ and quinones ${ }^{18,19)}$. $\mathrm{H}_{2} \mathrm{O}_{2}$ plays the most crucial role in the cascade of oxidative events induced by dopamine or levodopa ${ }^{20)}$. Quinones were suggested to be responsible in part for the degeneration of non-dopaminergic neurons ${ }^{21)}$. Their levels correlated positively with the severity of cell death in human neuroblastoma NB69 cells and the damage of dopaminergic neurons took place early before the rising of quinones. In addition to generation of $\mathrm{H}_{2} \mathrm{O}_{2}$ and quinone formation, levodopa-induced cell death may result from induction of apoptosis as evidenced by the increase in caspase- 3 activity in Neuro-2A cells ${ }^{22}$. Taken together, levodopa-induced toxicity is related primarily to dopamine production. Excessive dopamine metabolism by high-dose levodopa therapy may promote oxidative stress and thereby accelerate the rate of neuronal degeneration either in vivo or in vitro. Interestingly, Muriel et $a .^{23,24)}$ observed that levodopa treatment of control and lesioned rats with 6-OHDA altered the localization of the $\mathrm{D}_{1}$ dopamine receptor from the plasma membrane into the cytoplasm. The altered localization of $\mathrm{D}_{1}$ receptors may participate in the occurrence of the side effects of levodopa therapy such as dyskinesia and fluctuations in motor performance.

\section{Dopamine receptors as a target in PD-therapy}

Dopamine receptors belong to two classes (D1 and D2) of $\mathrm{G}$ protein-coupled receptors. The classification of dopamine receptors is primarily based on their effects on adenylyl cyclase activity and cAMP accumulation in the cells ${ }^{25}$. The D1 receptor subtypes promote, whereas the D2 subtypes inhibit adenylyl cyclase activity and cAMP synthesis ${ }^{26)}$. It has been reported that the D2 receptors are mainly responsible for modulating the activity of voltagesensitive $\mathrm{Ca}^{2+}$ and $\mathrm{K}^{+}$channels ${ }^{27}$. Dopamine receptor agonists play an important role in anti-Parkinsonian therapy and have become increasingly popular since the introduction of bromocriptine by Calne and colleagues in $1974^{28)}$. Their development aimed at reducing the unwanted motor complications produced by levodopa therapy ${ }^{29)}$. Dopamine receptor agonists are being used in the initial treatment of patients with de novo PD either as 
monotherapy or combined with low doses of levodopa ${ }^{30)}$. Moreover, dopamine agonists are advantageous in several aspects. They do not require carrier-mediated transport in the gut or brain. They act directly on dopamine receptors without the need for metabolic modification, release or storage. They also have longer half-lives than levodopa and therefore produce more persistent dopamine receptor stimulation than levodopa. Their metabolism does not generate free radicals which are considered one of the most important hazards in levodopa treatment particularly on dopaminergic neurons ${ }^{31)}$. The most important dopamine receptor agonists which are currently approved and gained access into the clinic and research studies are ergoline derivatives such as bromocriptine, lisuride, pergolide, cabergoline and á-dihydroergocryptine as well as the recently used non-ergoline derivatives like rotigotine, pramipexole, ropinirole and apomorphine. Ergolines, derivatives of ergot alkaloids, have a longer history in anti-Parkinsonian therapy and are as effective as nonergolines, which were developed in the hope that they might provide benefits of the ergoline agents without their side effects ${ }^{32)}$. Partly, the individual dopamine agonists show significant variation in their receptor affinity ${ }^{33)}$.

There is increasing evidence in the literature that dopamine agonists are not only beneficial to delay levodopa therapy in early Parkinsonism or to counteract its complications after long-term use but they have also been proposed to be neuroprotective particularly in experimental models ${ }^{34,35}$. The mechanisms and processes underlying the neuroprotective actions of dopamine agonists appear to be interlaced. They spare levodopa, thereby reducing the formation of oxidative radicals from levodopa metabolism, act as radical scavengers, reduce dopamine synthesis, release and metabolism via activating presynaptic autoreceptors, ameliorate excitotoxicity by suppressing subthalamic nucleus overactivity and exert antiapoptotic effects.

\section{Ginseng - a natural product and its active ingredients}

Ginseng refers to the roots of several species in the plant genus Panax (C. A. Meyer Araliaceae). Among them, Panax ginseng is the most widely used ginseng and is indigenous to the Far East countries (most notably Korea and China). Panax ginseng has a medical history of more than five thousand years. The genus name of Panax ginseng "Panax" was given by the Russian botanist C.A. Meyer, and is derived from the Greek words "pan" meaning all and "axos" meaning cure. The species name "ginseng" comes from the Chinese word "rensheng" which

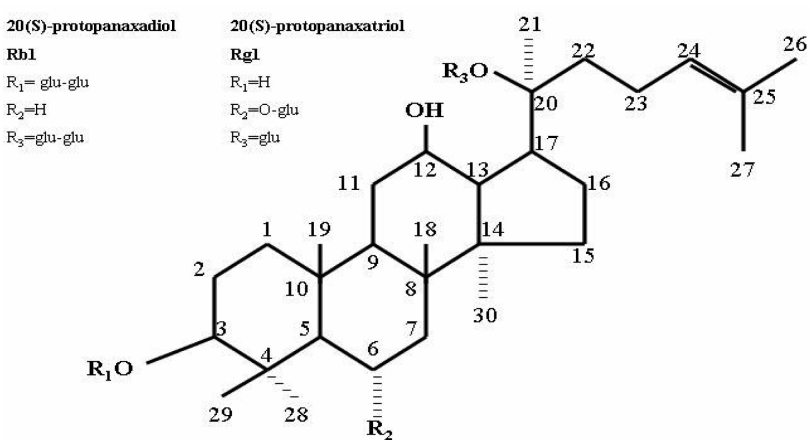

Fig. 1. Chemical structures of both ginsenosides $\mathrm{Rb}_{1}$ and $\mathrm{Rg}_{1}$. Ginsenoside $R b_{1}$ is an example for 20(S)-protopanaxadiol type while $\mathrm{Rg}_{1}$ for $20(\mathrm{~S})$-protopanaxatriol type.

means "human" as ginseng roots resemble the human body ${ }^{36)}$.

Ginsenosides or ginseng saponins are the principle active ingredients in ginseng and more than thirty different ginsenosides have been identified ${ }^{37,38}$. They consist of a gonane steroid nucleus with 17 carbon atoms arranged in four rings (see Fig. 1). The characteristic biological responses for each ginsenoside are attributed to the differences in the type, position and number of sugar moieties attached by glycosidic bond at C-3 and C-6 (Fig. 1). Based on their structural differences, they can be classified into three categories: the panaxadiol group (e.g. $\mathrm{Rb}_{1}$, $\mathrm{Rb}_{2}, \mathrm{Rb}_{3}, \mathrm{Rc}, \mathrm{Rd}, \mathrm{Rg}_{3}, \mathrm{Rh}_{2}, \mathrm{Rs}_{1}$ ), the panaxatriol group (e.g. $\mathrm{Re}, \mathrm{Rf}, \mathrm{Rg}_{1}, \mathrm{Rg}_{2}, \mathrm{Rh}_{1}$ ), and the oleanolic acid group (e.g. Ro $)^{39,40)}$.

\section{General effects attributed to ginseng}

Ginseng products are commonly used as general tonic and adaptogen to help the body to resist the adverse influences of a wide range of physical, chemical and biological factors and to restore homeostasis ${ }^{36,41)}$. These tonic and adaptogenic effects of ginseng are believed to enhance physical performance including sexual function and general vitality in healthy individuals, to increase the body's ability to fight stress in stressful circumstances and to support resistance to diseases by strengthening normal body function as well as to reduce the detrimental effects of the aging processes ${ }^{42,43)}$.

Ginseng rescues neuronal cells either in vivo or in vitro

Recently, it has been shown that ginseng and its components, ginsenosides, have a wide range of actions in the central nervous system ${ }^{44)}$. These effects include increased cell survival, extension of neurite growth and rescuing of 
neurons from death due to different insults either in vivo or in vitro. Sugaya et al. ${ }^{45)}$, Himi et $a l .{ }^{46)}$ and Mizumaki et $a l .{ }^{47)}$ reported that ginseng roots appeared to facilitate survival and neurite extension of cultured cortical neurons and $\mathrm{Kim}$ et al. ${ }^{48)}$ showed that ginsenosides $\mathrm{Rb}_{1}$ and $\mathrm{Rg}_{3}$ protected neurons from glutamate-induced neurotoxicity. Following forebrain ischaemia in gerbils, Wen et al. ${ }^{49)}$ and Lim et al. ${ }^{50)}$ demonstrated that central infusion of ginsenoside $\mathrm{Rb}_{1}$ rescued hippocampal CA1 neurons from lethal damage by cellular hypoxia. Using a spinal neuron model, ginsenosides $\mathrm{Rb}_{1}$ and $\mathrm{Rg}_{1}$ proved to be effective therapeutic agents for spinal cord injuries as they protected spinal neurons from excitotoxicity induced by glutamate and kainic acid and oxidative stress induced by hydrogen peroxide ${ }^{51)}$.

\section{Ginseng's role in Parkinson's disease models}

A number of studies have recently described the beneficial effect of ginseng and its main components, ginsenosides, on different neurodegenerative disease models. Special interest has been paid to PD models either in vivo or in vitro. In an in vivo model, Van Kampen et al. ${ }^{52)}$ reported that prolonged oral administration of ginseng extract G115 significantly protected against neurotoxic effects of parkinsonism-inducing agents such as 1-methyl4-phenyl-1,2,3,6-tetrahydropyridine (MPTP) and its active metabolite 1-methyl-4-phenylpyridinium $\left(\mathrm{MPP}^{+}\right)$in rodents. They found that ginseng-treated animals sustained less damage and $\mathrm{TH}^{+}$neuronal loss in substantia nigra pars compacta $(\mathrm{SNpc})$ after $\mathrm{MPP}^{+}$exposure. Likewise reduction of TH immunoreactivity in striatum was effectively diminished as a result of ginseng treatment compared to $\mathrm{MPP}^{+}$exposed animals. Similarly, striatal dopamine transporter (DAT) was significantly preserved due to ginseng treatment.

Our studies have used primary dopaminergic cells ${ }^{53)}$. Such nerve cell cultures can be prepared from embryonic mouse brains on gestation day 14 . These cells grow in serum and later serum-free conditions and differentiate into complex neuronal structures, which can be kept viable up to one month. Dopaminergic cells are characterized by immunohistochemistry as tyrosine hydroxylase positive structures. These cells however only represent a small part in culture and coexist with other neurons (e.g. gabaergic) and glial elements as predominantly astrocytes. Trophic properties by ginsenoside $\mathrm{Rb}_{1}$ can be demonstrated in our cultures (Fig. 2). The addition of $\mathrm{Rb}_{1}$ $(10 \mu \mathrm{M})$ results in $20 \%$ increased neurite lengths, a result which indicates growth stimulation or acceleration. As we

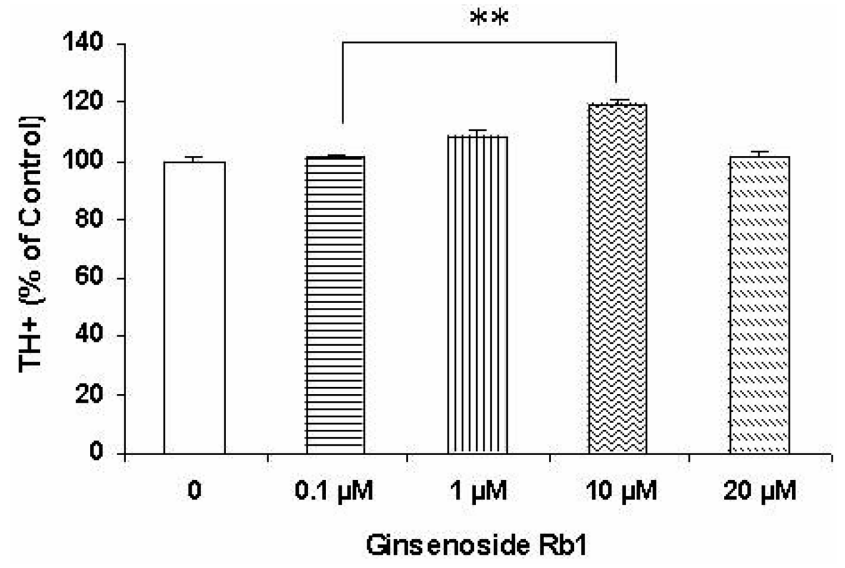

Fig. 2. Effect of ginsenoside $R b_{1}$ on the survival of dopaminergic neurons. Ginsenoside $\mathrm{Rb}_{1}(0.1,1,10,20 \mu \mathrm{M})$ was added to the cultures for six consecutive days (6th-12th DIV). About $100 \%$ corresponds to the total number of $\mathrm{TH}^{+}-$ neurons after 12 DIV in untreated controls. Values represent the mean \pm SEM for three independent experiments with four wells in each treatment. Statistical differences were determined with Kruskal-Wallis (H)test followed by $\chi^{2}$ test $(* * \mathrm{p}<0.01)$.

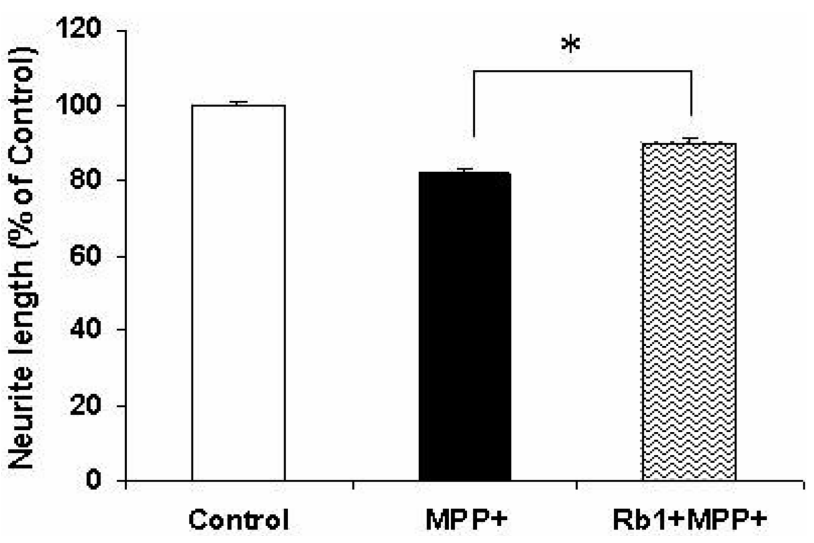

Fig. 3. Effects of ginsenosides $R b_{1}$ on the neurite growth of $\mathrm{MPP}^{+}$-treated dopaminergic cells. Ginsenoside $\mathrm{Rb}_{1}$ $(10 \mu \mathrm{M})$ was added on the $6^{\text {th }}$ DIV for 6 consecutive days and the cultures were exposed to $\mathrm{MPP}^{+}(1 \mu \mathrm{M})$ on the $10^{\text {th }}$ $\mathrm{DIV}$ for $48 \mathrm{~h}$. Ginsenoside $\mathrm{Rb}_{1}$ significantly promoted the neurite growth of dopaminergic cells. $100 \%$ corresponds to neurite lengths (longest neurite/cell) of $\mathrm{TH}^{+}$-cells after 12 DIV in untreated control. Values represent the mean \pm SEM for three independent experiments. Value of each experiment is the mean of the longest neurite of 30 cells in different four wells. Statistical differences were determined by the Wilcoxon test. $\left({ }^{*} \mathrm{p}<0.05\right)$

could show in our previous study ${ }^{53)} \mathrm{MPP}^{+}$concentrations of $1 \mu \mathrm{M}$ decrease dopaminergic cell counts by about 40 
$\%$. Looking at neurite lengths of dopaminergic cells (Fig. 3 ) the reduction of cellular processes by $\mathrm{MPP}^{+}$was effectively attenuated by ginsenoside $\mathrm{Rb}_{1}$. Considering extrapolations of such cell culture data to the in vivo situation could mean that a substantial part of affected neurons can be rescued or kept alive for a longer time span.

As to elucidate the processes and mechanisms underlying the neuroprotective effects of ginseng for dopaminergic neurons, several reports demonstrate the inhibitory role of ginseng on $\mathrm{MPP}^{+}$uptake in dopaminergic neurons, the suppression of oxidative stress induced by autooxidation of dopamine, the attenuation of $\mathrm{MPP}^{+}$-induced apoptosis and the potentiation of nerve growth factor action. Ginsenosides inhibit dopamine uptake into rat synaptosomes $^{54)}$ and consequently ginseng could potentially provide protection against $\mathrm{MPP}^{+}$through blockade of its uptake by dopaminergic neurons ${ }^{44)}$. Ginsenoside $\mathrm{Rg}_{1}$ may interrupt dopamine-induced elevation of reactive oxygen species or nitrogen oxide generation in pheochromocytoma cells ${ }^{55)}$. Kim et al. ${ }^{56)}$ and Chen et al. ${ }^{57)}$ reported that ginseng attenuated $\mathrm{MPP}^{+}$-induced apoptosis as it decreased the intensity of $\mathrm{MPP}^{+}$-induced DNA laddering in PC12 cells and ginsenoside $\mathrm{Rg}_{1}$ had protective effect against MPTP-induced apoptosis in the mouse substantia niga. This anti-apoptotic effect of ginseng may be attributed to enhanced expression of Bcl-2 and Bcl-xl, reduced expression of bax and nitric oxide synthase and inhibited activation of caspase-3. Ginseng may also reverse the neurotoxic effects of $\mathrm{MPP}^{+}$through elevation of NGF mRNA expression $^{44)}$. In accordance, Salim et al. ${ }^{58)}$ showed that ginsenosides $\mathrm{Rb}_{1}$ and $R g_{1}$ elevate NGF mRNA expression in rat brain and Rudakewich et al. ${ }^{59)}$ concluded that both ginsenosides potentiate NGF-induced neurite outgrowth in cell culture. Ginsenosides $\mathrm{Rb}_{1}, \mathrm{Rg}_{1}, \mathrm{Rc}$ and $\mathrm{Re}$ inhibited tyrosine hydroxylase activity and exhibited antidopaminergic action since they reduced the availability of dopamine at presynaptic dopamine receptors ${ }^{60)}$.

Glutamate as an excitotoxin may contribute to neuronal death in PD

Excitotoxic events could be important triggers for cell death in PD. Given the sensitivity of a disturbed dopaminergic system, overactivities of other transmitter systems may contribute to neurodegeneration. Glutamate is a major neurotransmitter in the mammalian nervous system. It plays an important role in many physiological functions including brain development and learning ${ }^{61,62)}$. On the other hand, glutamate is known to be a potent neurotoxin when present in excess at synapses ${ }^{63)}$ and glutamate exci- totoxicity has been shown to contribute to neuronal degeneration in acute conditions such as stroke, epilepsy, trauma, hypoxia and hypoglycaemia and chronic neurodegenerative diseases such as PD but also Alzheimer's and Huntington's diseases and amytrophic lateral sclerosis ${ }^{64)}$. The whole pathogenesis of glutamate toxicity is not fully understood. There is general agreement that it is $\mathrm{Ca}^{2+}$ dependent and the N-methyl-D-aspartate (NMDA) subtype of glutamate receptors plays a key role in mediating at least a certain aspect of glutamate toxicity ${ }^{65)} \cdot \mathrm{Ca}^{2+}$ loading exceeding the capacity of $\mathrm{Ca}^{2+}$ regulating mechanisms could activate several cell death-related genes and pathways ${ }^{66)}$. These include calcium-dependent activation of nucleases, lipases, proteases and neuronal nitric oxide synthase thus increasing oxidative stress ${ }^{67)}$. In 1992 , Albin and Greenamyre ${ }^{68)}$ introduced the concept of "weak excitotoxicity" postulating that also physiologic concentrations of glutamate can cause an excitotoxic influx of calcium when reduced ATP levels lead to disturbed cellular ion homeostasis, depolarized membrane potential and consequently release of the voltage-dependent $\mathrm{Mg}^{2+}$ blockade of the NMDA receptor, since a defect in complex I activity of the mithochondrial respiratory chain was reported in substantia nigra of Parkinsonian brains ${ }^{69)}$. This mechanism might well contribute to the degeneration of dopaminergic neurons. Additionally, increased glutamate release in the substantia nigra might also contribute to the damage of dopaminergic neurons since they are rich in glutamate receptors and receive glutamatergic input from cortex and subthalamic nucleus. The progressive dopamine deficiency during the course of PD is supposed to cause a disinhibition of the subthalamic nucleus thereby increasing excitotoxic damage in the substantia nigra ${ }^{70)}$.

\section{Ginsenosides reduce excitotoxicity in vitro}

In our studies on glutamate excitotoxicity ${ }^{71)}$, primary cultures from embryonic mouse mesencephala were exposed to a neurotoxic glutamate concentration and protective effects of these two ginsenosides on survival and neuritic growth of dopaminergic cells were tested. Treatment of primary mesencephalic culture with $500 \mu \mathrm{M}$ glutamate for $15 \mathrm{~min}$ increased the release of lactate dehydrogenase (LDH) into the culture medium, propidium iodide uptake by the cells and the total number of nuclei with condensed and fragmented chromatin (as apoptotic characteristics) as evaluated with Hoechst 33342. Moreover, glutamate extensively decreased the number of tyrosine hydroxylase immunopositive cells and adversely affected the length and number of their neuronal pro- 


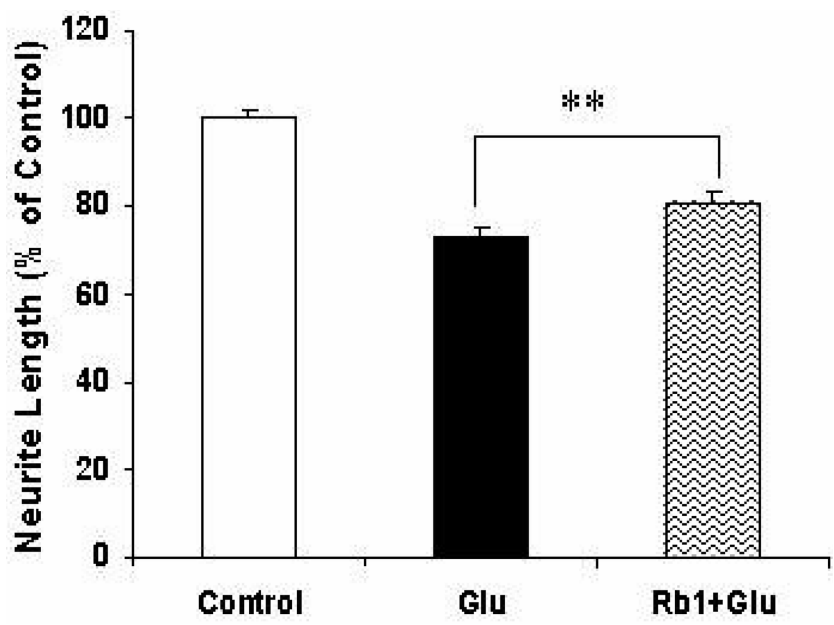

Fig. 4. Effect of ginsenoside $\mathrm{Rb}_{1}$ on neurite growth of glutamatetreated dopaminergic cells. Ginsenoside $\mathrm{Rb}_{1}(10 \mu \mathrm{M})$ was added on the 6th DIV for 4 consecutive days followed by glutamate treatment $(500 \mu \mathrm{M})$ for $15 \mathrm{~min}$ on the 10th DIV. Ginsenoside $\mathrm{Rb}_{1}$ significantly increased the neurite growth of dopaminergic cells following glutamate treatment. $100 \%$ corresponds to neurite lengths of $\mathrm{TH}^{+}$cells in untreated controls. Values represent the mean \pm SEM of three independent experiments. Value of each experiment is the mean of the neurite lengths of 30 cells in four wells. Statistical differences were determined by Wilcoxon test $(* * \mathrm{p}<0.01)$.

cesses. The toxic effect of glutamate was primarily mediated by over-activation of $\mathrm{N}$-methyl-d-aspartate receptor (NMDA) as treatment of cultured cells with (+)MK 801, a NMDA receptor antagonist, nearly abolished the dopaminergic cell loss and LDH release induced by glutamate. When added alone for six consecutive days (at final concentrations $0.1,1,10,20 \mu \mathrm{M}$ ), ginsenoside $\mathrm{Rb}_{1}$ (at 10 $\mu \mathrm{M})$ significantly enhanced the survival of dopaminergic neurons compared to untreated controls. Against glutamate exposure, ginsenosides $R b_{1}$ and $\mathrm{Rg}_{1}$ could not prevent cell death. However when pre-treating for 4 days or posttreating for 2 days following glutamate exposure, they significantly increased the numbers and lengths of neurites of surviving dopaminergic cells. Fig. 4 shows such a regenerative effect of ginsenoside $R b_{1}$. When given four days of regeneration following a glutamate insult, cell lengths regenerate about $50 \%$ better in the presence of 10 $\mu \mathrm{M} \mathrm{Rb}{ }_{1}$. Thus our study indicates that ginsenosides $R b_{1}$ and $\mathrm{Rg}_{1}$ exert partial neurotrophic and neuroprotective effects in dopaminergic cell culture.

Effect on neurotransmitter changes by ginsenosides PD has biochemically been characterized as a loss of dopamine in different dopaminergic nuclei however concomitant losses of other transmitters as noradrenaline and serotonin reflect a general underlying neurodegeneration. A number of studies have shown that ginsenosides can modulate neurotransmission in the brain. Both ginsenosides $\mathrm{Rb}_{1}$ and $\mathrm{Rg}_{1}$, can modulate acetylcholine release and re-uptake and the number of choline uptake sites especially in the hippocampus ${ }^{71)}$. They also increase choline acetyltransferase levels in rodent brains ${ }^{72)}$. Such data indicate that these compounds may improve central cholinergic function in humans and may be used to treat memory deficits ${ }^{59)}$. Ginsenosides increased dopamine and norepinephrine in cerebral cortex ${ }^{59)}$ which may explain the favorable effects of ginseng extract upon attention, cognitive processing, integrated sensory-motor function and auditory reaction time in healthy subjects ${ }^{73,74)}$. Additionally, it has been shown that ginseng total saponins modulates dopaminergic activity at both presynaptic and postsynaptic receptors ${ }^{75)}$, and blocks behavioral sensitization induced by psychostimulants such as morphine ${ }^{76}$, cocaine $^{77)}$, methamphetamines ${ }^{78)}$ and nicotine ${ }^{79}$. Ginseng increased serotonin in the cortex ${ }^{80)}$, ginseng saponins raised the levels of biogenic amines in normal rat brain ${ }^{81)}$, ginsenoside $\mathrm{Rg}_{2}$ directly interacted with nicotinic receptor subtypes $^{82)}$ and ginseng administration led to regulation of GABAergic transmission in animals ${ }^{83,84)}$.

\section{Effects of ginsenosides on cognitive decline}

Though the loss of motor functions is most evident at onset of PD, a concomitant decline of mental and cognitive functions has to be accepted. The use of herbal medicine, particularly ginseng, for improving cognitive performance has become increasingly popular during recent years and some studies have shown its enhancing effects on learning and memory either in aged and/or brain damaged individuals ${ }^{85,86}$. For example, significant improvement in learning and memory has been observed in aged and brain-damaged rats after local administration of ginseng powder ${ }^{87)}$. In humans, Terasawa et ${ }^{8{ }^{88}}{ }^{87}$ have shown that ginseng or ginseng extract had significant effects on neurological and psychiatric symptoms in aged humans and psychomotor functions in healthy subjects respectively. This positive effect of ginseng on cognition performance is owing to the direct action of ginseng on the hippocampus ${ }^{89)}$. Moreover, Shen and Zhang ${ }^{90)}$ suggested that the influence of ginsenoside $\mathrm{Rg}_{1}$ on the proliferating ability of neuronal progenitor cells may serve as an important mechanism underlying its nootropic and anti-aging effects particularly on learning and memory. 
This still appears controversial, as in healthy individuals Persson $e a^{a l}{ }^{91)}$ reported that regular use of ginseng during long period of time (up to 2 years) by healthy participants did not provide quantifiable beneficial effects on memory performance.

\section{Concluding remarks}

The worldwide use of ginseng as a medical herb and its intake by many healthy individuals to invigorate their bodies are based primarily on its empirical history in contributing to the recovery from a wide range of disease conditions particularly in the Far East countries. Yet, recent experimental research provides detailed indications of neuroprotective properties in cell culture systems and animal studies.

Parkinson's disease is a chronic neurodegenerative disorder characterized by progressive loss of dopaminergic neurons in the substantia nigra. The destruction of the dopaminergic system results in diminished dopamine levels in the striatum, the main target of dopaminergic projections. The actual treatment of parkinsonism is aimed at stopping nigral cell death ("neuroprotection") or to restore the function of remaining neurons ("neurorestoration"). To date, only the relief of Parkinsonian symptoms, particularly in the first five years after onset of the disease, has been achieved with levodopa, the dopamine precursor. Although levodopa replacement therapy is effective to compensate loss of dopamine in the striatum, the initial success is soon overshadowed by decreased efficacy and appearance of motor complications Thus for PD it appears essential to affect the slow progressive loss of dopaminergic neurons caused by oxidative stress, excitotoxicity, neuroinflammation and possibly also long term medication. Ginsenosides are compounds which have been shown in neuronal cell cultures and animal models to counteract these phenomena. Though such data are stimulating, it is clearly a long way from in vitro data to proven neuroprotective action in a human disease. It will remain to validated data from the clinic and here particularly imaging techniques as to actually prove, if the postulated neuroprotective actions of ginseng and/or their ingredients have such a desired effectivity in neurodegenerative disorders as PD.

\section{REFERENCES}

1. Paulus, W. and Jellinger, K.: The neuropathologic basis of different clinical subgroups of Parkinson's disease. J. Neuropathol. Exp. Neurol. 50, 743-755. (1991)
2. Yuan, H., Sarre, S., Ebinger, G. and Michotte, Y.: Neuroprotective and neurotrophic effect of apomorphine in the striatal 6-OHDA-lesion rat model of Parkinson's disease. Brain Res. 1026, 95-107 (2004).

3. Jenner, P., Schapira, A. H. and Marsden, C. D.: New insights into the cause of Parkinson's disease. Neurology 42, 22412250 (1992).

4. Olanow, C. W.: A radical hypothesis for neurodegeneration. Trends Neurosci. 16, 439-444 (1993).

5. Birkmayer, W. and Hornykiewicz, O.: The effect of 1-3,4dihydroxyphenylalanine (= DOPA) on akinesia in parkinsonism.. Wien. Klin. Wochenschr. 113, 851-854 (1961).

6. Chase, T. N., Mouradian, M. M. and Engber, T. M.: Motor response complications and the function of striatal efferent systems. Neurology 4, 23-27 (1993).

7. Nutt, J. G.: Clinical pharmacology of levodopa-induced dyskinesia. Ann. Neurol. 47, 160-164 (2000).

8. Metman, L. V., Konitsiotis, S. and Chase, T. N.: Pathophysiology of motor response complications in Parkinson's disease: hypotheses on the why, where, and what. Mov. Disord. 15, 3-8 (2000).

9. Ling, Z. D., Pieri, S. C. and Carvey, P. M.: Comparison of the neurotoxicity of dihydroxyphenylalanine stereoisomers in cultured dopamine neurons. Clin. Neuropharmacol. 19, 360365 (1996).

10. Mytilineou, C., Han, S. K. and Cohen, G.: Toxic and protective effects of L-dopa on mesencephalic cell cultures. J. Neurochem. 61, 1470-1478 (1993).

11. Hefti, F., Melamed, E., Bhawan, J. and Wurtman, R.: Longterm administration of L.dopa does not damage dopaminergic neurons in the mouse. Neurology 31, 1194-1195 (1981).

12. Perry, T. L., Yong, V. W., Ito, M., Foulks, J. G., Wall, R. A., Godin, D. V. and Clavier, R. M.: Nigrostriatal dopaminergic neurons remain undamaged in rats given high doses of LDOPA and carbidopa chronically. J. Neurochem. 43, 990-993 (1984).

13. Quinn, N., Parkes, D., Janota, I. and Marsden, C. D.: Preservation of the substantia nigra and locus coeruleus in a patient receiving levodopa $(2 \mathrm{~kg}$ ) plus decarboxylase inhibitor over a four-year period. Mov. Disord. 1, 65-68. (1986).

14. Zigmond, M. J., Hastings, T. G. and Perez, R. G.: Increased dopamine turnover after partial loss of dopaminergic neurons: compensation or toxicity? Parkinsonism Rel. Disord. 8, 389-393 (2002).

15. Dziewczapolski, G., Murer, G., Agid Y., Gershanik, O. and Raisman-Vozari, R.: Absence of neurotoxicity of chronic LDOPA in 6-hydroxydopamine-lesioned rats. Neuroreport $\mathbf{8}$, 975-979 (1997).

16. Murer, M. G., Dziewczapolski, G., Menalled, L. B., Garcia, M. C., Agid, Y., Gershanik, O. and Raisman-Vozari, R.: Chronic levodopa is not toxic for remaining dopamine neu- 
rons, but instead promotes their recovery, in rats with moderate nigrostriatal lesions. Ann. Neurol. 43, 561-575 (1998).

17. Ferrario, J. E., Delfino, M. A., Stefano, A. V., Zbarsky, V., Douhou, A., Murer, M. G., Raisman-Vozari, R. and Gershanik, O. S.: Effects of orally administered levodopa on mesencephalic dopaminergic neurons undergoing a degenerative process. Neurosc.i Res. 47, 431-436 (2003).

18. Spina, M. B. and Cohen, G.: Exposure of striatal synaptosomes to L-dopa increases levels of oxidized glutathione. $J$. Pharmacol. Exp. Ther. 247, 502-507 (1988).

19. Fahn, S. and Cohen, G.: the oxidant stress hypothesis in Parkinson's disease: Evidence supporting it. Ann. Neurol. 32, 804-812 (1992)

20. Lai, C. T. and Yu, P. H.: Dopamine- and L-beta-3,4-dihydroxyphenylalanine hydrochloride (L-Dopa)-induced ctoxicity towards catecholaminergic neuroblastoma SH-SY5Y cells: Effects of oxidative stress and antioxidative factors. Biochem. Pharmacol. 53, 363-372 (1997).

21. Pardo, B., Mena, M. A. and de Yebenes, J. G.: L-dopa inhibits complex IV of the electron transport chain in catecholamine-rich human neuroblastoma NB69 cells. J. Neurochem. 64, 576-582 (1995).

22. Pedros, R. and Soares-da-Silva, P.: Oxidative and non-oxidative mechanisms of neuronal cell death and apoptosis by L3,4-dihydroxyphenylalanine (L-DOPA) and dopamine. $\mathrm{Br}$. $\mathrm{J}$. Pharmacol. 137, 1305-1313 (2002).

23. Muriel, M. P., Bernard, V., Levey, A. I., Laribi, O., Abrous, D. N., Agid, Y., Bloch, B. and Hirsch, E. C.: Levodopa induces a cytoplasmic localization of D1 dopamine receptors in striatal neurons in Parkinson's disease. Ann. Neurol. 46, 103-111 (1999).

24. Muriel, M. P., Orieux, G. and Hirsch, E. C.: Levodopa but not ropinirole induces and internalization of D1 dopamine receptors in parkinsonian rats. Mov. Disord. 17, 1174-1179 (2002).

25. Kebabian, J. W. and Calne, D. B.: Multiple receptors for dopamine. Nature 277, 93-96 (1979).

26. Missale, C., Nash, S. R., Robinson, S. W., Jaber, M. and Caron, M. G.: Dopamine receptors: from structure to function. Physiol. Rev. 78, 189-225 (1998).

27. Sokoloff, P. and Schwartz, J. C.: Novel dopamine receptors half a decade later. Trends Pharmacol. Sci. 16, 270-275 (1995).

28. Foley, P., Gerlach, M., Double, K. L. and Riederer, P.: Dopamine receptor agonists in the therapy of Parkinson's disease. J. Neural Transm. 111, 1375-1446 (2004).

29. Jenner, P.: Dopamine agonists, receptor selectivity and dyskinesia induction in Parkinson's disease. Curr. Opin. Neurol. 16, 3-7 (2003).

30. Reichmann, H.: Long-term treatment with dopamine agonists in idiopathic Parkinson's disease. J. Neurol. 247 [Suppl 4], 17-19 (2000).
31. Gille, G., Rausch, W. D., Hung, S. T., Moldzio, R., Janetzky, B., Hundemer, H. P., Kolter, T. and Reichmann, H.: Pergolide protects dopaminergic neurons in primary culture under stress conditions. J. Neural Transm. 109, 633-643 (2002).

32. Bonuccelli, U.: Comparing dopamine agonists in Parkinson's disease. Curr. Opin. Neurol. 16, 13-19 (2003).

33. Gerlach, M., Double, K., Arzberger, T., Leblhuber, F., Tatschner, T. and Riederer, P.: Dopamine receptor agonists in current clinical use: comparative dopamine receptor binding profiles defined in the human striatum. J. Neural Transm. 110, 1119-1127 (2003).

34. Le, W. D. and Jankovic, J.: Are dopamine receptor agonists neuroprotective in Parkinson's disease? Drugs Ageing 18, 389-296 (2001).

35. Pirtosek, Z. and Flisar, D.: Neuroprotection and dopamine agonists. Adv. Exp. Med. Biol. 541, 55-74 (2004).

36. Noverino, E., Amato, M. and Izzo, A. A.: The aphrodisiac and adaptogenic properties of ginseng. Fitoterapia 71: 1-5 (2000).

37. Yun, T. K.: Brief introduction of Panax ginseng C.A. Meyer. J. Korean Med. Sci. 16: 53-55 (2001).

38. Rhim, H., Kim, H., Lee, D. Y., Oh, T. H. and Nah, S. Y.: Ginseng and ginsenoside $\mathrm{Rg}_{3}$, a newly identical active ingredient of ginseng, modulate $\mathrm{Ca}^{2+}$ channel currents in rat sensory neurons. Eur. J. Pharmacol. 463, 151-158 (2002).

39. Wen, T. C., Yoshimura, H., Matsuda, S., Lim, J. H. and Sakanaka, M.: Ginseng root prevents learning disability and neuronal loss in gerbils with 5-minute forebrain ischaemia. Acta Neuropathol. 91, 15-22 (1996).

40. Tachikawa, E., Kudo, K., Harada, K., Kashimoto, T., Miyate, M. and Kakizaki, A.: Effects of ginseng saponins on responses induced by various receptor stimuli. Eur. J. Pharmacol. 369, 23-32. (1999).

41. Blumenthal, M.: Asian ginseng: potential therapeutic uses. Adv. Nurse Pract. 2, 26-28 (2001).

42. Chu, G. X. and Chen, X.: Anti-lipid peroxidation and protection of ginsenosides against cerebral ischemia-reperfusion in rats. Zhongguo Yao Li Хие Bao 11, 119-123 (1990).

43. Tyler, V. E.: The Honest Herbal-A Sensible Guide to the Use of Herbs and Related Remedies. Third ed. The Haworth Press, New York (1993).

44. O'Hara, M., Kiefer, D., Farrell, K. and Kemper K.: A review of 12 commonly used medicinal herbs. Arch Fam Med 7, 523-536 (1998).

45. Sugaya, A., Yuzurihara, M., Tsuda, T., Yasuda, K., Kajiwara, K. and Sugaya, A. E.: Proliferative effect of ginseng saponin on neurite extension of primary cultured neurons of the rat cerebral cortex. J. Ethnopharmacol. 22,173-181(1988).

46. Himi, T., Saito, H. and Nishiyama, N.: Effects of ginseng saponins on the survival of cerebral cortex neurons in cell cultures. Chem. Pharm. Bull. (Tokyo) 37, $481-484$ (1989). 
47. Mizumaki, Y., Kurimoto, M., Hirashima, Y., Nishijima, M., Kamiyama, H., Nagai, S., Takaku, A., Sugihara, K., Shimizu, M. and Endo, S.: Lipophilic fraction of Panax ginseng induces neuronal differentiation of PC12 cells and promotes neuronal survival of rat cortical neurons by protein kinase $\mathrm{C}$ dependent manner. Brain Res. 20, 254-260 (2002).

48. Kim, Y. C., Kim, S. R., Markelonis, G. J. and Oh, T. H.: Ginsenosides $\mathrm{Rb}_{1}$ and $\mathrm{Rg}_{3}$ protect cultured rat cortical cells from glutamate-induced neurodegeneration. J. Neurosci. Res. 4, 426-432 (1998).

49. Wen, T. C., Yoshimura, H., Matsuda, S., Lim, J. H. and Sakanaka, M.: Ginseng root prevents learning disability and neuronal loss in gerbils with 5-minute forebrain ischaemia. Acta Neuropathol. 91, 15-22 (1996).

50. Lim, J. H., Wen, T. C., Matsuda, S., Tanaka, J., Maeda, N., Peng, H., Aburaya, J., Ishihara, K. and Sakanaka, M.: Protection of ischaemic hippocampal neurons by ginsenosides $\mathrm{Rb}_{1}$, a main ingredient of ginseng root. Neurosci. Res. 28, 191-200 (1997).

51. Liu, C. X. and Xiao, P. G.: Recent advances on ginseng research in China. J. Ethnopharmacol. 36, 27-38 (1992).

52. Van Kampen, J., Robertson, H., Hagg, T. and Drobitch, R.: Neuroprotective actions of the ginseng extract G115 in two rodent models of Parkinson's disease. Exp. Neurol. 184, 2129 (2003).

53. Radad, K., Gille, G. Moldzio R., Saito, H, Ishige K. and Rausch, W. D.: Ginsenosides $\mathrm{Rb}_{1}$ and $\mathrm{Rg}_{1}$ effects on survival and neurite growth of $\mathrm{MPP}^{+}$-affected mesencephalic cells. $J$. Neural Transm. 111, 37-45 (2004)

54. Tsang, D., Yeung, H. W., Tso, W. W. and Peck, H.: Ginseng saponins: influence on neurotransmitter uptake in rat brain synaptosomes. Planta Med. 3, 221-224 (1985).

55. Chun, C. X., Gui, Z. Y., An, Z. L., Chun, H., Ying, C., Min, C. L., Fang, F., Can, Z. Y. and Hui, Z. C.: Ginsenoside Rg $_{1}$ attenuates dopamine-induced apoptosis in PC12 cells by suppressing oxidative stress. Eur. J. Pharmacol. 473, 1-7 (2003).

56. Kim, E. H., Jang, M. H., Shin, M. C., Shin, M. S. and Kim, C. J.: Protective effect of aqueous extract of Ginseng radix against 1-methyl-4-phenylpyridinium-induced apoptosis in PC12 cells. Biol. Pharm. Bull. 26, 1668-1673 (2003).

57. Chen, X. C., Chen, Y., Zhu, Y. G., Fang, F. and Chen, L. M.: Protective effect of ginsenoside $\mathrm{Rg}_{1}$ against MPTP-induced apoptosis in mouse substantia nigra neurons. Acta Pharmacol. Sin. 23, 829-834 (2002).

58. Salim, K. N., McEven, B. S. and Choa, H. M.: Ginsenoside $\mathrm{Rb}_{1}$ regulates ChAT, NGF and trkA mRNA expression in the rat brain. Brain Res. Mol. Brain Res. 47, 177-182 (1997).

59. Rudakewich, M., Ba, F. and Benishin, C. G.: Neurotrophic and neuroprotective actions of ginsenosides $R b_{1}$ and $R g_{1}$. Planta Med . 67, 533-537 (2001).

60. Kim, H. S., Zhang, Y. H., Fang, L. H. and Lee, M. K.: Effects of ginsenosides on bovine adrenal tyrosine hydroxylase. $J$. Ethnopharmacol. 66, 107-111 (1999).

61. Bliss, T. V. and Collingridge, G. L.: A synaptic model of memory: long-term potentiation in the hippocampus. Nature 361, 31-39 (1993).

62. Malenka, R. C. and Nicoll R. A.: NMDA-receptor-dependent synaptic plasticity: multiple forms and mechanism. Trends Neurosci. 16, 521-527 (1993).

63. Plaitakis, A. and Shashidharan, P.: Glutamate transport and metabolism in dopaminergic neurons of substantia nigra: implications for the pathogenesis of Parkinson's disease. $J$. Neurol. 247. 1125-1135 (2000).

64. Lipton, S. A. and Rosenberg, P. A.: Excitatory amino acids as a final common pathway for neurologic disorders. Engl. J. Med. 330, 613-622 (1994).

65. Sattler, R. and Tymiansky, M.: Molecular mechanism of calcium dependent excitotoxicity, J. Mol. Med. 78, 3-13 (2000).

66. Said, S. I., Pakbaz, H., Berisha, H. I. and Raza, S.: NMDA receptor activation: critical role in oxidant tissue injury. Free Radic. Bio. Med. 28, 1300-1302 (2000).

67. Doble, A.: The role of excitotoxicity in neurodegenerative disese: implication for therapy. Pharmacol. Ther. 81, 163221 (1999).

68. Albin, R. L. and Greenamyre, J. T.: Alternative excitotoxic hypotheses. Neurology 42, 733-738 (1992).

69. Mizuno, Y., Ohta, S., Tanaka, M., Takamiya, S., Suzuki, K., Sato, T., Oya, H., Ozawa, T. and Kagawa, Y.: Deficiencies in complex I subunits of the respiratory chain in Parkinson's disease. Biochem. Biophys. Res. Commun. 163, 1450-1455 (1989).

70. Rodriguez, M. C., Obeso, J. A. and Olanow, C. W.: Subthalamic nucleus mediated excitotoxicity in Parkinson's disease: a target for neuroprotection. Ann. Neurol. 44, 175-188 (1998).

71. Radad, K., Gille, G., Moldzio, R., Saito, H. and Rausch, W. D.: Ginsenosides $\mathrm{Rb}_{1}$ and $\mathrm{Rg}_{1}$ effects on mesencephalic dopaminergic cells stressed with glutamate. Brain Res. 1021, 41-53 (2004).

72. Benishin, C. G.: Actions of ginsenoside $\mathrm{Rb}_{1}$ on choline uptake in central cholinergic nerve endings. Neurochem. Int. 21, 1-5 (1992).

73. Itoh, T., Zang, Y. F., Murai, S. and Saito, H.: Effects of Panax ginseng root on the vertical and horizontal motor activities and on brain monoamine-related substances in mice. Planta Med. 55, 429-433 (1989).

74. D’Angelo, L., Grimaldi, R., Caravaggi, M., Marcoli, M., Perucca, E., Lecchini, S., Frigo, G.M. and Crema, A.: A double-blind, placebo-controlled clinical study on the effect of a standardized ginseng extract on psychomotor performance in healthy volunteers. J. Ethnopharmacol. 16, 15-22 (1986). 
75. Kim, H. S., Kang, J. G., Seong, Y. H., Nam, K. Y. and Oh, K. $\mathrm{W}$.: Blockade by ginseng total saponins of the development of cocaine induced reverse tolerance and dopamine receptor supersensitivity in mice. Pharmacol. Biochem. Behav. 50, 23-27 (1995).

76. Kim, H. S., Kang, J. G. and Oh, K. W.: Inhibition by ginseng total saponins of the development of morphine reverse tolerance and dopamine receptor supersensitivity in mice. Gen. Pharmacol. 26,1071-1076 (1995).

77. Kim, H. S., Kang, J. G., Seong, Y. H., Nam, K. Y. and Oh, K. $\mathrm{W}$.: Blockade by ginseng total saponins of the development of cocaine induced reverse tolerance and dopamine receptor supersensitivity in mice. Pharmacol. Biochem. Behav. 50, 23-27 (1995).

78. Kim, H. S., Hong, Y. T., Oh, K. W., Seong, Y. H., Rheu, H. M. and Cho, D. H.: Inhibition by ginsenosides $\mathrm{Rb}_{1}$ and $\mathrm{Rg}_{1}$ of methamphetamine-induced hypersensitivity, conditioned place preference and post-synaptic dopamine receptor supersensitivity on mice. Gen. Pharmacol. 30, 783-789 (1998).

79. Shim, I., Won, J., Song, J., Kim, S. E. and Huh, S.: Modulatory effect of ginseng total saponins on dopamine release and tyrosine hydroxylase gene expression induced by nicotine in the mouse. J. Ethnopharmacol. 70, 161-169 (2000).

80. Petkov, V.: Effect of ginseng on the brain biogenic monoamines and 3',5'-AMP system. Experiments on rats. Arzneimittelforschung 28, 388-393 (1978).

81. Wang, A., Cao, Y., Wang, Y., Zhao, R. and Liu, C.: Effects of Chinese ginseng root and stem-leaf saponins on learning, memory and biogenic monoamines of brain in rats. Zhongguo Zhong Yao Za Zhi 20, $493-495$ (1995).

82. Sala, F., Mulet, J., Choi, S., Jung, S. Y., Nah, S. Y., Rhim, H., Valor, L. M., Criado, M. and Sala, S.: Effects of ginsenoside $\mathrm{Rg}_{2}$ on human neuronal nicotinic acetylcholine receptors. $J$.
Pharmacol. Exp. Ther. 301, 1052-1059 (2002).

83. Kimura, T., Saunders, P. A., Kim, H. S., Rheu, H. M., Oh, K. W. and Ho, I. K.: Interactions of ginsenosides with ligandbindings of GABA(A) and GABA(B) receptors. Gen. Pharmacol. 25, 193-199 (1994).

84. Choi, S. E., Choi, S., Lee, J. H., Whiting, P. J., Lee, S. M. and Nah, S. Y.: Effects of ginsenosides on GABA(A) receptor channels expressed in Xenopus oocytes. Arch. Pharm. Res. 26, 28-33 (2003).

85. Yamaguchi, Y., Higashi, M. and Kobayashi, H.: Effects of ginsenosides on impaired performance caused by scopolamine in rats. Eur. J. Pharmacol. 312,149-151 (1996).

86. Mook-Jung, I., Hong, H. S., Boo, J. H., Lee, K. H., Yun, S. H., Cheong, M. Y., Joo, I., Huh, K. and Jung, M. W.: Ginsenoside $\mathrm{Rb}_{1}$ and $\mathrm{Rg}_{1}$ improve spatial learning and increase hippocampal synaptophysin level in mice. J. Neurosci. Res. 63, 509-915 (2001).

87. Kennedy, D. O. and Scholey, A. B.: Ginseng: potential for the enhancement of cognitive performance and mood. Pharmacol. Biochem. Behav. 75, 687-700 (2003).

88. Terasawa, K., Shimada, Y. and Kita, T.: Choto-san in the treatment of vascular dementia: a double blind, placebo-controlled study. Phytomedicine 4,15-22 (1997).

89. Kurimoto, H., Nishijo, H., Uwano, T., Yamaguchi, H., Zhong, Y. M., Kawanishi, K. and Ono, T.: Effects of nonsaponin fraction of red ginseng on learning deficits in aged rats. Physiol. Behav. 82,345-355 (2004).

90. Shen, L. and Zhang, J.: Ginsenoside $\operatorname{Rg}_{1}$ increases ischemiainduced cell proliferation and survival in the dentate gyrus of adult gerbils. Neurosci. Lett. 344, 1-4 (2003).

91. Persson, J., Bringlov, E., Nilsson, L. G. and Nyberg, L.: The memory-enhancing effects of Ginseng and Ginkgo biloba in healthy volunteers. Psychopharmacology 172, 430-434 (2004). 